\title{
Diagnóstico de la ehrlichiosis monocítica canina: una revisión actualizada
}

\section{Diagnosis of canine monocytotropic ehrlichiosis: an update review}

Fecha de recepción: 5 de octubre de 2014

Fecha de aceptación: 28 de noviembre de 2014
Roger Iván Rodríguez-Vivas', Manuel Emilio Bolio-González², Melina Maribel Ojeda-Chi ${ }^{3}$

\section{Resumen}

La ehrlichiosis monocítica canina (EMC) es causada por la infección de una rickettsia denominada Ehrlichia canis; este microorganismo se reproduce solamente en el citoplasma de los monocitos sanguíneos y macrófagos tisulares. La EMC ha sido reportada en todo el mundo, pero las frecuencias más altas se reportan en las regiones tropicales y subtropicales. La EMC no siempre es reconocida clínicamente, pues es difícil de diagnosticar debido a que los signos clínicos son variables, a que se presenta en diferentes fases y a la existencia de coinfecciones con otros patógenos transmitidos por garrapatas y otros agentes infecciosos. Las manifestaciones clínicas y las técnicas de diagnóstico tradicionales, como el diagnóstico hematológico y la demostración típica de mórulas de $E$. canis en el citoplasma de monocitos en frotis sanguíneos, se han utilizado para el diagnóstico de la EMC; sin embargo, las pruebas de diagnóstico por PCR y la serología mediante el uso de antígenos específicos son las pruebas más sensibles y específicas para el diagnóstico de la enfermedad. Este artículo presenta una revisión actualizada sobre el diagnóstico de la infección por $E$. canis en perros.

Palabras clave: Ehrlichia canis, Enfermedades caninas, Trombocitopenia, Diagnóstico molecular, Ensayo de Inmunoadsorción Enzimática.

\begin{abstract}
1 Ph. D. Universidad Autónoma de Yucatán (Yucatán, México).rvivas@uady.mx.

2 Ph. D. Universidad Autónoma de Yucatán (Yucatán, México).bgonza@uady.mx.

3 M. Sc. Universidad Autónoma de Yucatán (Yucatán, México).
\end{abstract}

Canine monocytic ehrlichiosis (CME) is caused by the infection with a rickettsial organism, Ehrlichia canis. This organism is replicated only in the cytoplasm of blood monocytes and tissue macrophages. CME has been reported throughout the world but at higher frequencies in tropical and subtropical regions. CME is often under-recognized since the disease is difficult to diagnose due to variable clinical signs, its diffe- 
rent stages, and frequent co-infection with other tick-borne pathogens or other infectious agents. Clinical manifestations and the traditional diagnostic techniques such as hematology and demonstration of typical cytoplasmic E. canis-morulae in monocytes in blood smears have been used for the diagnosis of CME; however, the PCR-based diagnostic tests and serology methods based on specific antigens, are the most sensitive and specific for this disease. This article reviews the current literature covering the diagnosis of infection by $E$. canis in dogs.

Key words: Ehrlichia canis, dogs diseases, thrombocytopenia, molecular diagnostic techniques, Inmuneadsortion Enzimatic test. 


\section{Introducción}

La ehrlichiosis es una enfermedad causada por bacterias rickettsiales del género Ehrlichia, las cuales son microorganismos Gram negativos, intracelular obligados, de estructuras pleomórficas y que se localizan intracelularmente en leucocitos y plaquetas. Actualmente existen cinco especies reconocidas: Ehrlichia canis, E. chaffeensis, E. ewingii, E. muris y E. ruminantium. Ehrlichia canis causa la ehrlichiosis monocítica canina (EMC) $(1,2)$.

Clínicamente, la ehrlichiosis puede cursar en tres fases: aguda, subclínica y crónica. La primera ocurre luego del período de incubación, pudiendo existir una recuperación total o inducir a una fase subclínica, en la que no es posible observar signos evidentes a pesar de que el agente persiste dentro del hospedero. La fase crónica puede seguir a la fase subclínica, con difícil recuperación del paciente. Los signos clínicos de la EMC varían, dependen de la fase en que se encuentre el paciente $(3,4)$; los más frecuentes son: hipertermia, anorexia, emaciación, hepatomegalia, esplenomegalia, linfadenopatía y alteraciones respiratorias, cardiacas, nerviosas y oculares, así como alteraciones hematológicas que incluyen, entre otros, anemia, leucopenia y trombocitopenia (4-7). La EMC es una enfermedad de distribución mundial. La prevalencia y seroprevalencia de $E$. canis en perros varía de $3-45 \%$ y $2-88 \%$, respectivamente, dependiendo de la prueba de diagnóstico utilizada, condiciones climáticas y distribución de su vector, Rhipicephalus sanguineus $(2,4,8)$.

Debido a que la EMC es una enfermedad sistémica con diferentes fases y manifestaciones clínicas, su diagnóstico es complicado. Se sospecha de EMC cuando el perro tiene antecedentes de estar expuesto a garrapatas Rhipicephalus sanguineus y presenta manifestaciones clínicas sistémicas típicas de la enfermedad (2). Son útiles en el diagnóstico de la enfermedad la citología, la serología, el aislamiento del agente y las técnicas de diagnóstico que se realizan mediante la identificación de la bacteria en monocitos (detección de mórulas), así como de las alteraciones en valores hematimétri- cos; sin embargo, el diagnóstico definitivo de $E$. canis requiere de técnicas moleculares $(2,3)$.

Para obtener la información actualizada sobre el diagnóstico de la EMC producida por $E$. canis en perros se realizó una búsqueda en la base de datos Medline, utilizando los descriptores "Ehrlichia canis" y "diagnosis". Para aumentar la recuperación de citas médicas veterinarias adicionales se realizó la búsqueda en google académico, usando los mismos términos; también se realizaron búsquedas en libros y manuales de bacteriología. La búsqueda se limitó a los artículos en inglés y español. Se consultaron los artículos de 2005 a la fecha; sin embargo, se incluyeron las referencias previas cuando la información se consideró relevante. La búsqueda en Medline y google académico arrojaron, respectivamente, 184 y 1030 artículos científicos sobre el tema.

La presente revisión tiene como objetivo presentar al lector la información actualizada del diagnóstico de la EMC producida por E. canis en perros.

\section{Agente Etiológico}

Ehrlichia canis es un microorganismo intracelular obligado del orden Rickettsiales, encontrado principalmente en sangre periférica; las bacterias individuales miden $<0.5 \mu \mathrm{m}$ de diámetro; parasitan y se replican por fisión binaria dentro de una vacuola citoplasmática de la célula mononuclear, formando microcolonias o mórulas en los monocitos circulantes y macrófagos. Las mórulas pueden contener pocos o varios microrganismos individuales, alcanzando hasta $4.6 \mu \mathrm{m}$ de diámetro (8-9). En la fase crónica de la enfermedad es poco probable detectar las mórulas en los animales infectados (10).

El genoma de $E$. canis consiste de un solo cromosoma circular compuesto de 1,315, 030 nucleótidos (11); tiene 984 genes, incluyendo una copia de cada uno de los genes de los ácidos ribonucléicos ribosomales (rRNA) 5S, 165 y 23S. Los genes $5 S$ y $23 S$ forman un operón, mientras el gen $16 S$ está separado; esta característica es rara en los genomas bacterianos, que típicamente presentan de una a múltiples copias de rRNAs contenidas en operones 
16S-23S-5S. Las otras dos especies pertenecientes al genogrupo $E$. canis son $E$. chaffeensis y E. ewingii, que pertenecen a la familia Anaplasmataceae, del orden Rickettsiales, y comparten una similitud de más del $97 \%$ en la secuencia del gen 165 rRNA, así como varias proteínas que expresan epítopos inmunogénicos similares, razón que comúnmente provoca reacciones cruzadas entre miembros de este genogrupo en pruebas serológicas $(11,12)$.

\section{Aspectos inmunológicos de interacción huésped-agente etiológico}

La etapa del proceso de invasión de $E$. canis en las células hospedadoras incluye: adhesión, internalización y proliferación intracelular, seguida de exocitosis y difusión intercelular. En el proceso de adherencia e internalización a la célula hospedadora están involucradas varias proteínas de membrana externa de $E$. canis, incluyendo la glicoproteína (gp) 19, gp36 y gp140 (13). En el proceso de propagación intercelular se ha demostrado, en condiciones in vitro, que está involucrada la polimerización del citoesqueleto de actina en presencia de calcio y hierro $(14,15)$. Las gp36 and gp19 han demostrado incrementar la sensibilidad y proveen especificidad de especie en el inmunodiagnóstico en infecciones con E. canis (16).

\section{Diagnóstico clínico}

La EMC es una enfermedad multisistémica que se manifiesta de forma aguda, subclínica y crónica; sus manifestaciones son variables, dependiendo de factores como la diferencia de patogenicidad entre cepas de Ehrlichia, raza de perros, infecciones concomitantes con otras enfermedades transmitidas por garrapatas y el estado inmunitario del canino (2). La EMC presenta tres fases clínicas:

Fase aguda. Los signos clínicos suelen ser inespecíficos; incluso, pueden pasar inadvertidos. La fase aguda empieza a los 8-20 días posteriores a la inoculación del patógeno por picadura de la garrapata, con una duración de 2-4 semanas (17). Algunos de los hallazgos clínicos más característicos de esta fase es la trombocitopenia y trombocitopatías motivadas fundamentalmente por procesos inmu- nomediados, y ocurre en $>90 \%$ de los perros infectados $(15,18)$. Los signos clínicos son fiebre, apatía y decaimiento, anorexia, pérdida de peso y, en ocasiones, linfadenomegalia, esplenomegalia; se ha descrito la presentación de sintomatología respiratoria debida a la existencia de procesos inflamatorios y hemorrágicos: exudado oculonasal, disnea, cianosis y, a veces, aumento de la intensidad de los sonidos respiratorios $(2,5,6)$. Los perros pueden presentar tendencia al sangrado, petequias, equimosis en la piel y membranas mucosas, y ocasionalmente epistaxis. Pueden presentarse signos oculares que incluyen uveítis anterior más opacidad corneal (edema o depósito de precipitados celulares), hipema, tortuosidad de vasos retinales y lesiones corio-retinales focales (manchas pigmentadas rodeadas de áreas de hiperreflectividad). Puede haber desprendimiento de retina y ceguera, debido a hemorragias subretinales (19). Otros signos clínicos son intolerancia al ejercicio por neumonitis, vómitos, ataxia y claudicación. Suelen aparecer signos neurológicos como resultado de la meningitis o hemorragias en las meninges (3).

Fase subclínica. Esta fase puede durar entre 40 y 120 días o incluso años, pues los caninos pueden permanecer persistentemente infectados durante años sin presentar signos clínicos, pero con trombocitopenia leve (17); por esta razón, todavía no es claro cómo ciertos perros progresan a la fase crónica de la enfermedad.

Fase crónica. Esta fase puede acompañarse de manifestaciones leves o graves; la primera se manifiesta como una enfermedad vaga, con pérdida de peso y alteraciones hematológicas menos graves (20). En casos crónicos graves se describen signos clínicos como debilidad, depresión, anorexia, pérdida crónica de peso, palidez de mucosas, fiebre y edema periférico, especialmente en miembros posteriores y escroto. Sangrado por trombopatía, como petequias, equimosis dérmicas y de membranas mucosas y epistaxis, es hallazgo con frecuencia (3) (Figura 1). Las petequias cutáneas y en mucosas se observan de forma macroscópica en los animales infectados; microscópicamente, las hemorragias están presentes en casi todos los órganos del sistema; estas hemorragias son el resulta- 
do de la disfunción plaquetaria y trombocitopenia (21).

Los signos neurológicos pueden ocurrir tanto en la enfermedad aguda como crónica. Estos incluyen signos de meningoencefalitis, como, por ejemplo: lomo arqueado, dolor severo de cuello y lomo, paraparesia o tetraparesia, ataxia, déficit de nervios craneales y convulsiones. Los signos neurológicos pueden ser debidos a hemorragias, infiltración celular extensa y compresión perivascular de las meninges (3). También se describe la presentación de hemorragias internas, hematuria, hipema, hemorragia retiniana, hemoptisis, hematemesis, hemartrosis y hemorragia cerebral. La presencia de hemorragias en el miocardio puede producir síntomas cardíacos como taquicardia o diferentes arritmias que pueden acompañarse de una intensa disnea. Si la hemorragia o la anemia son severas, el animal puede presentar una marcada hipotensión que puede desencadenar un cuadro de shock (18). En esta fase la concentración de proteínas suele incrementarse (22). Asimismo, en la fase grave de la enfermedad se puede desarrollar pancitopenia, debido a hipocelularidad de médula ósea. Esta fase no es curable y su pronóstico es grave (15).
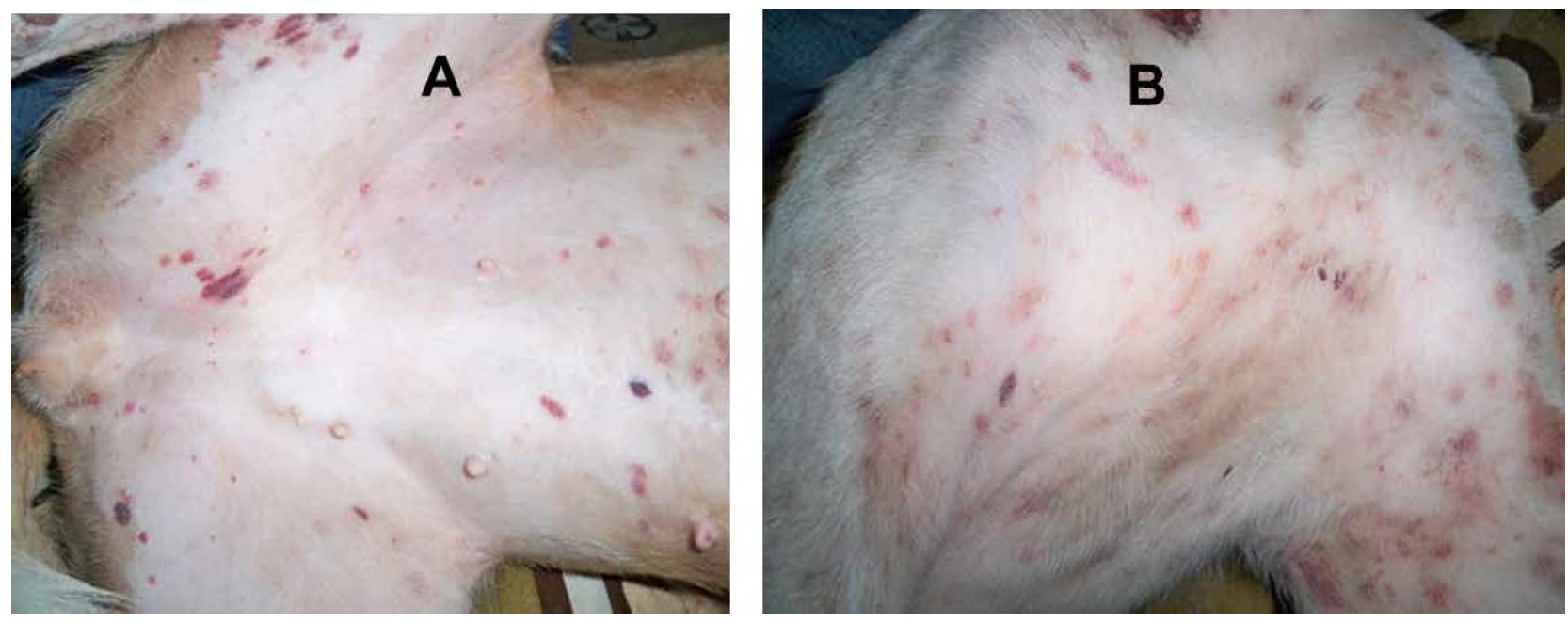

Figura 1. Hemorragias cutáneas en parte ventral del abdomen (a) y la parte ventral del tórax de un paciente canino positivo a Ehrlichia canis (fotografías donadas por Mvz. Julio Basulto Poot

\section{Diagnóstico de laboratorio de la infección por E. Canis}

\section{Diagnósticos indirectos}

Diagnóstico hematológico. En la fase aguda de la EMC participan fenómenos inmunológicos e inflamatorios con incremento en el consumo de plaquetas y disminución de la vida media de estas, tal vez como resultado de secuestro esplénico (23). Es posible que la IgG y los anticuerpos relacionados con las plaquetas que reconocen proteínas plaquetarias en canino infectados con $E$. canis tengan un papel importante en la trombocitopenia $(3,20)$. Además, se ha encontrado que en perros con ehrlichiosis existe una citocina sérica, Ilamada factor de inhibición de la migración plaquetaria (PMIF), y sus valores se relacionan de manera inversa a la cantidad de plaquetas; las concentraciones más altas de PMIF se relacionan con cepas más virulentas de $E$. canis. EI PMIF es elaborado por linfocitos cuando se exponen a monocitos infectados. La función de las plaquetas, medida mediante respuestas de agregación, está aunada a su cantidad, su disminución contribuye a la hemorragia (20). En la fase aguda de la EMC, la trombocitopenia moderada o severa es un hallazgo importante. Se diagnostica trombocitopenia con recuentos plaquetarios entre 20,000 a 30,000 plaquetas $/ \mu \mathrm{l}$. En un estudio realizado por Rodriguez-Vivas et al. (7) se encontró que perros seropositivos a $E$. canis tuvieron menor número de plaquetas que los perros seronegativos $(214,000 /$ 
$\mu$ y $310,000 / \mu 1$, respectivamente). La trombocitopenia es atribuida a diversos mecanismos que incluyen vasculitis, destrucción inmunomediada y secuestro plaquetario. La vasculitis y secuestro plaquetario se producen por el factor inhibidor de migración plaquetaria y la supresión en la producción de plaquetas (fase crónica), produciendo trombocitopenia (24). La serie roja se ve igualmente afectada, presentándose anemia debido al daño de la médula ósea y a la acelerada destrucción local y esplénica de los eritrocitos. Asimismo, se puede presentar crisis hemolíticas por la formación de anticuerpos o por una respuesta específica a antígenos de superficie de los eritrocitos (20). En este periodo, la anemia es, normalmente, regenerativa, ya que la médula ósea suele ser hipercelular. El recuento de leucocitos en sangre es variable; inicialmente se encuentra una ligera leucopenia debida al secuestro de leucocitos producido por procesos inmunológicos e inflamatorios. Esta leucopenia puede transformarse posteriormente en leucocitosis. La función de los leucocitos también puede verse alterada; los linfocitos de caninos con ehrlichiosis pueden producir un factor con efecto citotóxico sobre monocitos; esta sustancia podría ser similar a la que inhibe la formación de pseudópodos plaquetarios (18). Asimismo, se presentan niveles elevados de alanina aminotransaminasa (300 UI / L) y fosfatasa alcalina (2000 UI / L), los cuales son transitorios, pero característicos en esta fase $(25,26)$. En infecciones agudas de $E$. canis en caninos se incrementa la proteína total $(33 \%)$, la hipoalbuminemia (22\%) y la hipergamaglobulinemia $(68 \%)(27)$.

En la fase crónica de la EMC puede resultar en emaciación y con hipoplasia de la médula ósea, lo que ocasiona una pancitopenia (28). La gravedad de esta fase se ha venido asociando tanto con la trombocitopenia como con el grado de aplasia medular. La médula ósea suele estar afectada, presentando inicialmente una hipoplasia eritroide que da lugar a una anemia no regenerativa. La relación medular mieloide/eritroide suele estar aumentada, siendo típica la presencia de plasmocitosis debida a una estimulación antigénica crónica. A medida que el proceso se va haciendo más grave, la médula se irá afectando en todas sus líneas celulares, pudiéndose producir incluso una aplasia medular completa que determinará la presencia de un cuadro severo con pancitopenia, que suele desembocar en la muerte del paciente (18).

\section{Pruebas serológicas}

Existen varios métodos serológicos para el diagnóstico de EMC. La inmunofluorescencia indirecta (IFI) para la detección de anticuerpos IgG anti- $E$. canis es considerada la "prueba de oro", ya que indica la exposición previa del perro a $E$. canis. La detección de anticuerpos de la clase IgM no es considerada un indicador confiable a la exposición de $E$. canis, ya que existe una inconsistencia en el desarrollo de anticuerpos IgM en el curso de la enfermedad; además, los anticuerpos IgM pueden estar falsamente elevados, debido a otras infecciones ricketsiales (29). Se ha demostrado reacción cruzada de $E$. canis con $E$. chaffeensis y $E$. ewingii ya que tienen varias proteínas que expresan epítopos inmunogénicos similares $(11,12)$.

A diferencia de los anticuerpos IgG que se consideran más específicos para la detección de la EMC. Los niveles detectables de anticuerpos IgG generalmente aparecen hasta 7-10 días después de la aparición de la enfermedad (29). Según Waner et al. (30), los perros son considerados seronegativos si el título es menor de 1/40; ligeramente positivo, entre $1 / 40$ y $1 / 80$; moderadamente positivo, entre $1 / 160$ y $1 / 320$, y fuertemente positivo si el título es igual o superior a 1/640. En la infección aguda, dos pruebas de IFI, con diferencia de 7-14 días, es recomendable, y un aumento de 4 veces los títulos de anticuerpos es sugestivo a una infección activa. Los anticuerpos IgG persisten por varios meses o años después del tratamiento o la eliminación de la rickettsia (2).

El ensayo inmunoadsorbente ligado a enzima (ELISA, por sus siglas en inglés) ha sido usado para el diagnóstico serológico de la EMC. Harrus y Waner (2) compararon la prueba de IFI con tres diferentes pruebas de ELISA para detectar anticuerpos IgG anti-E. canis (detección de casos positivos): 1) un kit de ELISA basado en una proteína recombinante MAP2, 2) un dot-ELISA que usa un extracto crudo de Ehrlichia, 3) y una ELISA comercial que 
usa péptidos sintéticos derivados de las proteínas p30 y $p 30-1$. Las tres pruebas de ELISA y la prueba de IFI mostraron una concordancia de $74.6 \%$ (50 muestras positivas detectadas en las tres pruebas de ELISA de un total de 67 muestras positivas en la prueba de IFI). El $25.4 \%$ de las muestras fueron negativas a las pruebas de ELISA, cuando en la IFI tuvieron títulos de anticuerpos de $\leq 1: 320$. Los autores concluyeron que las tres pruebas de ELISA tienen buena sensibilidad y especificidad cuando los anticuerpos detectados por la IFI tienen títulos de $\geq 1: 320$. Por tal motivo, para reducir este problema de sensibilidad de las pruebas de ELISA se recomienda hacer un segundo diagnóstico 1-2 semanas después del primer diagnóstico (31). Harrus et al. (31) mencionan que la prueba comercial de ELISA (Snap 3DX ${ }^{\circledR}$ ) para el diagnóstico serológico de $E$. canis tiene una sensibilidad de $71 \%$ y una especificidad de $100 \%$.

Las reacciones cruzadas de anticuerpos anti-E. canis con otras especies de rickettsias han complicado el diagnóstico serológico de la EMC. Rikhisa et al. (32) mencionan que los anticuerpos anti-E. canis reaccionan con antígenos de Neorickettsia helminthoeca y $N$. risticii. Asimismo, Krawczak et al. (33) mencionan que puede existir reacción cruzada entre los géneros Leishmania, Babesia y Ehrlichia. La prueba de ELISA no puede discriminar entre anticuerpos de $E$. canis, $E$. ewingii, $E$. chaffeensis y E. ruminnatium (16). Sin embargo, no existe reacción cruzada entre anticuerpos anti-E. canis y antígenos de $A$. phagocytophilum y $A$. platys (34).

Otras pruebas serológicas han sido usadas para el diagnóstico de $E$. canis. Western blot ha sido usada para distinguir entre infecciones por $E$. canis y $E$. ewingii. Esto es importante, ya que la mayoría de los perros con infección a $E$. ewingii tendrán títulos de anticuerpos anti-E. canis en la prueba de IFI (2).

La prueba rápida de inmunomigración o inmunocromatografía detecta las interacciones antígeno-anticuerpo, y tiene la ventaja de ser almacenada a temperatura ambiente (entre $2{ }^{\circ} \mathrm{C}$ y $25^{\circ} \mathrm{C}$ ). La prueba rápida de testigo es otra técnica que ha demostrado alta sensibilidad ( $97 \%$ ) y especificidad
$(100 \%)$, y a diferencia de IFI, que es larga y costosa, es simple, práctica y rápida (10 minutos) (26).

Varios péptidos específicos de especies del género Ehrlichia han sido identificados y usados para estudios moleculares y serológicos. Gusa et al. (35) identificaron el gen p28 de E. ewingii y encontraron que este péptido podría usarse como especie específica para estudios moleculares de la bacteria. Posteriormente, O'Connor et al. (36) usaron el $p 28$ para detectar anticuerpos específicos anti- $E$. ewingii en caninos infectados natural y experimentalmente. Por otra parte, Sumner et al. (37) clonaron, secuenciaron y expresaron el gen VLPT ("variable-length PCR target") de E. chaffeensis, este gen demostró ser un marcador sensible y específico de $E$. chaffeensis. El antígeno $p 16$ es reconocido por los sueros de perros infectados con $E$. canis y ha demostrado ser un antígeno específico para detectar $E$. canis en perros (38). Recientemente se han usado los péptidos específicos de especie para detectar anticuerpos anti-Ehrlichia, los cuales son: p30/p30-1E para Ehrlichia spp; $p 16$ para E. canis, VLPT para $E$. chaffeensis y $p 28$ para $E$. ewingii $(39,40)$. Estos péptidos específicos de especie han sido usados para detectar anticuerpos anti-Ehrlichia en caninos de Estados Unidos, Canadá y en el Caribe (40).

\section{Diagnósticos directos}

Frotis sanguíneos: los frotis sanguíneos consisten en extender una pequeña gota de sangre sobre un portaobjetos, y teñirla con un colorante (ejemplo, Giemsa al 10\%) para su posterior observación al microscopio óptico, usando el lente de 100X. Los monocitos son observados en busca de cuerpos de inclusión intracitoplasmáticas (mórulas). Esta técnica resulta rápida, sencilla y económica; sin embargo, aproximadamente, solo en el $4 \%$ de los casos agudos de EMC es posible demostrar los cuerpos de inclusión intracitoplasmáticos de E. canis (2, 7). La mejor forma de detectar E. canis en frotis sanguíneo es mediante el uso de la capa flogística. Cuando se quiere observar mórulas de $E$. canis se recomienda usar aspirados de linfonódulos, que deben ser examinados por un experto en citología, logrando obtener un alto rango de detección de 
hasta el 50\% $(41,42)$. Mylonakis et al. (41), al usar la capa flogística en frotis sanguíneos encontraron un $66 \%$ de sensibilidad.

La observación de inclusiones intracitoplasmáticas de $E$. canis en monocitos es suficiente para realizar el diagnóstico definitivo de la ehrlichiosis; sin embargo, si no se observan las inclusiones en los frotis sanguíneos, y el perro presenta signos de la enfermedad, no se debe descartar la posibilidad de una EMC. Para confirmar los casos EMC es necesario recurrir a otras pruebas complementarias (ejemplo, serología y detección del agente por técnicas moleculares) (2).

\section{Diagnóstico microbiológico y cultivos celulares:} el aislamiento de $E$. canis a través de cultivos celulares ha permitido la caracterización citotóxica del agente para producir técnicas de diagnóstico serológico más sensibles y permitir la identificación de cepas de $E$. canis en distintas regiones del mundo $(2,43)$. La línea celular canina de macrófagos DH82 ha sido utilizada con éxito para el cultivo de E. canis. La prueba consiste en aislar de un caso clínico de EMC la fracción de células mononucleares de la capa flogística de la sangre. Las células mononucleares obtenidas se incuban a $37{ }^{\circ} \mathrm{C}$ en una atmósfera con $5 \%$ de $\mathrm{CO}_{2}$. Después las células mononucleares son puestas en contacto con células DH82 no infectadas (43).

En condiciones naturales, la infección por E. canis se produce tras la picadura del canino por una garrapata hematófaga. La rickettsia penetra la "célula blanco" a través de un proceso de fagocitosis y se multiplica por fisión binaria. Se observan dos formas morfológicas diferentes: las células de núcleo denso (CD) y las células reticuladas (CR). Las CD son las formas que entran en los monocitos del hospedero y predominan durante las primeras horas posinfección $(\mathrm{PI})$. Después de 24 horas PI solo se observan $\mathrm{CR}$, que son resultados de la fisión binaria. Cuanta y ocho horas PT las mórulas contienen varias $C R$ que son resultado de la extensiva fisión binaria. Las formas $C D$ vuelven a predominar a las 72 horas, correlacionadas con el tiempo en que son liberadas, para comenzar un nuevo ciclo (44).
De 3 a 5 días $\mathrm{PI}$ aparece un pequeño número de cuerpos elementales agrupados en forma de inclusiones pleomórficas, con un tamaño aproximado de 1.4 a 2 micras, los cuales reciben el nombre de cuerpos iníciales. Durante los 7-12 días siguientes continúa el crecimiento y la replicación de estos microorganismos, dando lugar a las mórulas (mayores de 2 micras), denominadas así por su típica forma (44). Las mórulas se encuentran rodeadas por una membrana que engloba un número variable de cuerpos elementales $(25,44)$. La destrucción de la célula hospedadora parece que tiene lugar cuando el citoplasma celular se encuentra repleto de microorganismos, lo que trae consigo una liberación de cuerpos elementales que invaden nuevas células (44).

En Brasil se han aislado y propagado en condiciones in vitro tres cepas de $E$. canis (45). Recientemente, Alves et al. (43) aislaron una cepa de $E$. canis en Brasil, usando las células DH82. Esto ha permitido la producción de antígenos para la prueba de IFI. Sin embargo, el cultivo in vitro de $E$. canis es laborioso y requiere de un laboratorio equipado y personal capacitado. El crecimiento de $E$. canis es lento y requiere de hasta 10 semanas después de iniciado en cultivo de $E$. canis. Sin embargo, Alves et al. (43), para poder aislar una cepa de $E$. canis mediante el uso de la línea celular canina de macrófagos $\mathrm{DH} 82$, requirieron de tan solo cuatro semanas. Por otra parte, líneas celulares endoteliales humanas (CDC/EU.HMEC-1) han sido usadas con éxito para el aislamiento de $E$. canis (46). El aislamiento en cultivo celular es considerado, sin embargo, como la "prueba de oro" para el diagnóstico serológico de ehrlichiosis (47).

Diagnóstico molecular: la prueba de reacción en cadena de la polimerasa (PCR, por sus siglas en inglés) y la secuenciación son métodos sensibles para la detección y caracterización molecular de E. canis. El resultado negativo denota que el sitio blanco del ADN no fue detectado; sin embargo, no necesariamente indica que el ADN no esté presente en la muestra (falso negativo). La detección de $A D N$ de $E$. canis se obtiene después de 4-10 días posinoculación. Los ensayos se basan en diferentes genes blanco (16S rRNA, p28, p30, dsb, 
VirB9), siendo los genes 165 rRNA y p30 los más usados. Ehrlichia canis contiene múltiples copias de gen $p 30$ y una copia de $16 S r R N A$, lo que incrementa la posibilidad de detectar $E$. canis si se emplea gen $p 30$ como blanco. Muchos estudios con el gen $16 S$ rRNA han proporcionado información sobre la diversidad de cepas de Ehrlichia y han demostrado que es un gen altamente conservado. Por otra parte, el gen de proteína que participa en la formación de enlaces disulfuro (dsb) o la función de los enlaces disulfuro inter- e intramoleculares también se pueden emplear para el diagnóstico de Ehrlichia; estos genes son altamente conservados entre las bacterias y las proteínas recombinantes dsb de Ehrlichia y se encuentran en el periplasma de $E$. chaffeensis y E. canis (46). La PCR realizada con muestras de bazo es más sensible para evaluar la eliminación de ehrlichia, en comparación de muestras de sangre y medula ósea. Las bacterias del género Ehrlichia, fundamentalmente $E$. canis, podrían permanecer secuestradas en células de tejidos del sistema mononuclear fagocitario, y se ha reportado que pueden persistir más tiempo en el bazo que en la sangre periférica (48); generalmente, las muestras empleadas en el diagnóstico rutinario proceden de sangre del paciente, por lo que se podrían obtener resultados negativos en sangre y existir $E$. canis secuestrada en otros tejidos (49). Gal et al. (50) sugieren que la sangre y los ganglios linfáticos son los tejidos de elección cuando se persigue el diagnóstico de EMC en la necropsia. Sin embargo, el uso del hígado o bazo como muestra para el diagnóstico aumenta la tasa de detección de este patógeno.

En infecciones experimentales, la rickettsemia de $E$. canis puede detectarse en los perros a los 7-12 días posinfección, con niveles más altos los días 10-12 días posinfección; los organismos ya no son detectados dos semanas después del inicio de la terapia con antibióticos (51).

Se recomienda emplear muestras de suero para el diagnóstico molecular de $E$. canis solo en caso de que las muestras de sangre no sean viables. La PCR que se realiza usando suero debe ser analizado por triplicado, empleando el gen $16 S$ rRNA (25).
La técnica de PCR tipo anidado ofrece la ventaja de poder determinar las especies E. canis, E. chaffeensis y $E$. ewingii utilizando el mismo producto de la primera reacción (52), tanto en muestras de caninos como de garrapatas (53-56). Un resultado negativo a la PCR tipo anidado, pero positivo a la prueba serológica, puede ser explicado por la capacidad que tiene este parásito de "ocultarse" en los macrófagos esplénicos (57). Recientemente, con la técnica de PCR tipo anidado se ha diagnosticado E. canis en perros y en garrapatas Rhipicephalus sanguineus (58).

La PCR de tiempo real es más sensible que la PCR convencional y cuantifica la cantidad de bacterias presentes; esta técnica es menos propensa a la contaminación que la PCR convencional y si se presenta la contaminación esta puede ser detectada por el análisis de fusión de curvas. La PCR de tiempo real es el método más rápido para el diagnóstico de $E$. canis.

Recientemente se han construido iniciadores quiméricos de ADN/RNA para el gen $165 r R N A$ de $E$. canis. Varias bases de RNA fueron incorporadas en posiciones específicas de los iniciadores del ADN mientras que no se incorporaron tramos de RNA; el empleo de los iniciadores quiméricos disminuyó la formación de subproductos indeseables y aumentó 10 veces la sensibilidad del ensayo (59). Asimismo, se ha empleado la PCR de tiempo real de disociación de alta resolución para discriminar entre diferentes especies y cepas de ehlichias. Peleg et al. (60) desarrollaron una prueba de PCR múltiple en tiempo real para detectar los genes $16 \mathrm{~S}$ $r R N A$ de $E$. canis y hsp70 de Babesia canis vogeli, y encontraron buenos resultados sin la necesidad de realizar amplificación previa de los genes. Esta prueba se recomienda para usarse en el diagnóstico de ambos agentes, lo que ayudaría a reducir los costos y tiempo.

La PCR de tiempo real también permite detectar simultáneamente varios patógenos en una muestra; sin embargo, se podría esperar una disminución de la sensibilidad por la presencia de reacciones múltiples en el ensayo (2). 
Debido a la secuencia de ADN, el gen 16S rRNA de $E$. canis se emplea únicamente para la identificación genética y no caracteriza la diversidad genómica del agente; en años recientes se ha empleado el gen gp36, que codifica una proteína inmunorreactiva para caracterizar nuevos aislamientos de E. canis (61-63).

El bazo ha sido identificado como la primera fuente de Ehrlichia para el diagnóstico y es considerado como el principal órgano para el diagnóstico molecular de la ehrlichiosis $(25,48)$. En un estudio realizado por Faria et al. (64), en perros que manifestaron trombocitopenia y signos clínicos de ECM, se encontró que los aspirados de bazo fueron mejores en la detección de infecciones por $E$. canis, pudiendo detectarse hasta un $48.5 \%$ de perros con mórulas de $E$. canis, mientras el $72.5 \%$ de los perros fueron positivos a la detección de ADN de $E$. canis por pruebas moleculares.

Recientemente, Muangchuen et al. (65) desarrollaron una técnica para la detección colorimétrica de $E$. canis a través de la hibridación en nanocoloides de oro. La técnica se basa en la amplificación del gen p30, usando la amplificación isotérmica en forma cíclica. La técnica fue específica y rápida para identificar la bacteria (90 min), pudiendo detectar 50 copias del ADN blanco.

\section{Conclusiones}

La EMC es una enfermedad sistémica de distribución mundial, con diferentes manifestaciones clínica, lo que complica su diagnóstico. La primera sospecha de EMC es cuando el perro se expone a infestaciones por la garrapata Rhipicephalus sanguineus y empieza a manifestar signos inespecíficos que se asocian con trombocitopenia y trombocitopatías. Los signos clínicos principales son fiebre, apatía, decaimiento, anorexia, pérdida de peso, disnea, cianosis y cuadros hemorrágicos. A nivel mundial existe abundante información sobre el diagnóstico de la EMC, siendo las pruebas serológicas las más usadas. Las técnicas tradicionales de diagnóstico mediante los signos clínicos, identificación de mórulas de $E$. canis en frotis sanguíneos, alteraciones en estudio de hemáticos y citología son herramientas útiles en el diagnósti- co de la enfermedad; sin embargo, las pruebas de diagnóstico por PCR y la serología mediante el uso de antígenos específicos son las más sensibles y específicas para el diagnóstico de la enfermedad.

\section{Referencias}

(1) Garrity GM, Bell JA, Lilburn TG. Taxonomic outline of the prokaryotes Bergey's manual of systematic bacteriology. Second edition, New York, Springer, 2004.

(2) Harrus S, Warner T. Diagnosis of canine monocytotropic ehrlichiosis (Ehrlichia canis): An overview. Vet J 2011; 187, 292-296.

(3) Harrus S, Waner T, Bark H, Jongejan F, Corneliensse AW. Recent advances in determining the pathogenesis of canine monocytic ehrlichiosis. J Clin Microbiol 1997; 37: 2745-2749.

(4) Harrus S. Perspectives on the pathogenesis and treatmentof canine monocytic ehrlichiosis (Ehrlichia canis). Vet J 2015; 204(3): 239-240.

(5) Sainz Á, Roura X, Miró G, Estrada-Peña A, Kohn $B$, Harrus $S$ et al. Guideline for veterinary practitioners on canine ehrlichiosis and anaplasmosis in Europe. Parasit Vectors 2015; 8: 75.

(6) René-Martellet M, Lebert I, Chêne J, Massot R, Leon M, Leal A. et al. Diagnosis and incidence risk of clinical canine monocytic ehrlichiosis under field conditions in Southern Europe. Parasit Vectors 2015; 8: 3.

(7) Rodríguez-Vivas RI, Albornoz REF, Bolio GME. Ehrlichia canis in dogs in Yucatan, México: seroprevalence, prevalence of infection and associated factors. Vet Parasitol 2005; 127(1): 75-79.

(8) Maazi N; Malmasi A, Shayan P, Nassiri SM, Salehi TZ, Fard MS. Molecular and serological detection of Ehrlichia canis in naturally exposed dogs in Iran: an analysis on associated risk factors. Rev Bras Parasitol, 2014; 23(1): 16-22. 
(9) Allison RW, Little SE. Diagnosis of rickettsial diseases in dogs and cats. Vet Clin Pathol 2013; 42(2): 127-144.

(10) Mylonakis ME, Koutinas AF, Breitschwerdt EB, Hegarty BC, Billinis CD, Leontides LS et al. Chronic canine ehrlichiosis (Ehrlichia canis): a retrospective study of 19 natural cases. J Am Anim Hosp Assoc, 2004; 40: 174-184.

(11) Mavromatis K, Doyle CK, Lykidis A, Ivanova $\mathrm{N}$, Francino MP, Chain $\mathrm{P}$ et al. The genome of the obligately intracellular bacterium Ehrlichia canis reveals themes of complex membrane structure and immune evasion strategies. J Bacteriol, 2006; 188: 4015-4023.

(12) Singu V, Peddireddi L, Sirigireddy KR, Cheng C, Munderloh U, Ganta RR. Unique macrophage and tick cell-specific protein expression from the p28/p30-outer membrane protein multigene locus in Ehrlichia chaffeensis and Ehrlichia canis. Cell Microbiol, 2006; 8: 14751487.

(13) McBride JW, Walker DH. Molecular and cellular pathobiology of Ehrlichia infection: Targets for new therapeutics and immunomodulation strategies. Exp Rev Mol Med, 2011; 13: 1-19.

(14) Alves RN, Levenhagen MA, Levenhagen MM, Rieck SE, Labruna MB, Beletti ME. The spreading process of Ehrlichia canis in macrophages is dependent on actin cytoskeleton, calcium and iron influx and lysosomal evasion. Vet Microbiol, 2014; 168: 442-446.

(15) Harrus S. Perspectives on the pathogenesis and treatment of canine monocytic ehrlichiosis (Ehrlichia canis). Vet J, 2015; 204(3): 239240.

(16) Cardenas AM, Doyle CK, Zhang X, Nethery $\mathrm{K}$, Corstvet RE, Walker et al. Enzyme-linked immunosorbent assay with conserved immunoreactive glycoproteins gp36 and gp19 has enhanced sensitivity and provides species-specific immunodiagnosis of Ehrlichia canis infec- tion. Clin Vaccine Immunol, 2007; 14: 123128.

(17) Skotarczak B. 2003. Canine Ehrlichiosis. Ann Agric Environ Med, 2003; 10: 137-141.

(18) Bulla C, Takahira RK, Araújo JP, Trinca LA, Lopes RS, Wiedmeyer CE. The relationship between the degree of thrombocytopenia and infection with Ehrlichia canis in an endemic area. Vet Res, 2004; 35: 141-146.

(19) Komnenou AA, Mylonakis ME, Kouti V, Tendoma L, Leontides L, Skountzou E et al. Ocular manifestations of natural canine monocytic ehrlichiosis (Ehrlichia canis): a retrospective study of 90 cases. Vet Ophthalmol, 2007; 10: 137-142

(20) Mark Neer T. Ehrlichiosis. En: Greene, Enfermedades infecciosas en perros y gatos. Capítulo 28. Segunda Edición, Ed. McGraw-Hill Interamericana. Philadelphia, USA 2000; pp. 153-161.

(21) de Castro MB, Machado RZ, de Aquino LP, Alessi AC, Costa MT. Experimental acute canine monocytic ehrlichiosis: clinicopathological and immunopathological findings. Vet Parasitol, 2004; 119: 73-86.

(22) Shimada $T$, Ishida $Y$, Shimizu $M$, Nomura $M$, Kawato K, Iguchi K, Jinbo T. Monitoring C-reactive protein in beagle dogs experimentally inoculated with Ehrlichia canis. Vet Res Commun, 2002; 26: 171-177.

(23) Gyles CL, Prescott JF, Songer JO, Thoen CO. Pathogenesis of bacterial infections in animals. Chapter 31. Third Edition. Iowa, USA 2004; pp. 429-431.

(24) Brandão LP, Hasegawa MY., Hagiwara MK., Kohayagawa A. Platelet aggregation studies in acute experimental canine ehrlichiosis. Vet Clin Pathol, 2006; 35(1): 78-81. 
(25) Waner T, Harrus S. Canine monocytic ehrlichiosis-from pathology to clinical manifestations. Isr / Vet Med, 2013; 68(1): 12-18.

(26) Davoust B, Parzy D, Demoncheaux JP, Tine R, Diarra M, Marié JL et al. Usefulness of a rapid immuno-migration test for the detection of canine monocytic ehrlichiosis in Africa. Comp Immunol Microbiol Infect Dis, 2014; 37(1): 31-37.

(27) Waner T, Harrus S, BarkH, Bogin E, Avidar Y, Keysary A. Characterization of the subclinical phase of canine ehrlichiosis in experimentally infected beagle dogs. Vet Parasitol, 1997; 69: 307-317.

(28) Bowman DD. Georgis' Parasitology for veterinarians. Ninth Edition. Chapter 5. Saunders Elsevier NY USA; 2009. pp. 244-246.

(29) McBride JW, Corstvet RE, Gaunt SD, Boudreaux C, Guedry T, Walker DH. Kinetics of antibody response to Ehrlichia canis immunoreactive proteins. Infect Immun, 2003; 71: 2516-2524.

(30) Waner T, Harrus S, Jongejan F, Bark H, Keysary A, Cornelissen AW. Significance of serological testing for ehrlichial diseases in dogs with special emphasis on the diagnostic of canine monocytic ehrlichiosis caused by Ehrlichia canis. Vet Parasitol, 2001; 95: 1-15.

(31) Harrus S, Alleman AR, Bark H, Mahan SM, Waner T. Comparison of three antibody test for the diagnosis of canine infection with Ehrlichia canis. Vet Microbiol, 2002; 8: 361-368.

(32) Rikihisa Y. Cross-reacting antigens between Neorickettsia helminthoeca and Ehrlichia species, shown by immunofluorescence and Western immunoblotting. J Clin Microbiol, 1991; 29: 2024-2029.

(33) Krawczak Fda S, Reis IA, Silveira JA, Avelar DM, Marcelino AP, Werneck GL et al. Leishmania, Babesia and Ehrlichia in urban pet dogs: co-infection or cross-reaction in serolog- ical methods? Rev Soc Bras Med Trop, 2015; 48(1): 64-68.

(34) Waner T, Strenger C, Keysary A, Harrus S. Kinetics of serologic crossreactions between $E$ hrlichia canis and the Ehrlichia phagocytophila genogroups in experimental $E$. canis infection in dogs. Vet Immunol Immunop, 1998; 66: 237-243.

(35) Gusa AA, Buller RS, Storch GA, Huycke MM, Machado LJ, Slater LN et al. Identification of a p28 gene in Ehrlichia ewingii: evaluation of gene for use as a target for a species-specific PCR diagnostic assay. J Clin Microbiol, 2001; 39: 3871-3876.

(36) O'Connor TP, Saucier JM, Daniluk D, Stillman BA, Krah R, Rikihisa Y et al. Evaluation of peptide- and recombinant protein-based assays for detection of anti-Ehrlichia ewingii antibodies in experimentally and naturally infected dogs. Am J Vet Res, 2010; 71: 1195-1200.

(37) Sumner JW, Childs JE, Paddock CD. Molecular cloning and characterization of the Ehrlichia chaffeensis variable-length PCR target: an antigen-expressing gene that exhibits interstrain variation. / Clin Microbiol, 1999; 37: 1447-1453.

(38) Beall MJ, Alleman RA, Breitschwerdt EB, Cohn LA, Couto CG, Dryden MW et al. Seroprevalence of Ehrlichia canis, Ehrlichia chaffeensis and Ehrlichia ewingii in dogs in North America. Parasit Vectors, 2012; 5: 29.

(39) Qurollo BA, Chandrashekar R, Hegarty BC, Beall MJ, Stillman B, Liu J et al. A serological survey of tick-borne pathogens in dogs in North America and the Caribbean as assessed by Anaplasma phagocytophilum, A. platys, Ehrlichia canis, E. chaffeensis, E. ewingii, and Borrelia burgdorferi species-specific peptides. Infect Ecol Epidemiol, 2014; 4: 24699.

(40) Starkey LA, Barrett AW, Chandrashekar R, Stillman BA, Tyrrell P, Thatcher B et al. Development of antibodies to and PCR detection 
of Ehrlichia spp. in dogs following natural tick exposure. Vet Microbiol, 2014; 173: 379-384.

(41) Mylonakis ME, Koutinas AF, Billinis C, Leontides LS, Kontos V, Papadopoulos $\mathrm{O}$ et al. Evaluation of cytology in the diagnosis of acute canine monocytic ehrlichiosis (Ehrlichia canis): a comparison between five methods. Vet Microbiol, 2003; 91(2-3): 197-204.

(42) Mylonakis ME, Borjesson DL, Leontides L, Siarkou VI, Theodorou K, Koutinas AF. Cytologic patterns of lymphadenopathy in canine monocytic ehrlichiosis. Vet Clin Pathol, 2011; 40(1): 78-83.

(43) Alves RN, Rieck SE, Ueira-Vieira C, Labruna $\mathrm{MB}$, Beletti ME. Isolation, in vitro propagation, genetic analysis, and immunogenic characterization of an Ehrlichia canis strain from southeastern Brazil. J Vet Scien, 2014a; 15(2): 241248.

(44) Tesouro DMA, Sainz R E. Etiología y transmisión. En: Ehrlichiosis canis et felis. Aula Veterinaria. 2001. Madrid, España. 51: 1.

(45) Aguiar DM, Hagiwara MK, Labruna MB. In vitro isolation and molecular characterization of an Ehrlichia canis strain from São Paulo, Brazil. Braz J Microbiol, 2008; 39: 489-493.

(46) Dawson JE, Candal FJ, George VG, Ades EW. Human endothelial cells as an alternative to DH82 cells for isolation of Ehrlichia chaffeensis, E. canis, and Rickettsia rickettsii. Pathobiol, 1993; 61: 293-296.

(47) Rivas LV, Morales AD, Saenz M, Bonilla JL. Hallazgo de Ehrlichiosis canina causada por $E$. canis en una Comunidad del municipio de León, Nicaragua. RedVet, 2010; 11(3): 1-10.

(48) Harrus S, Kenny M, Miara L, Aizenberg I, Waner T, Shaw S. Comparison of simultaneous splenic sample PCR with blood sample PCR for diagnosis and treatment of experimental Ehrlichia canis infection. Antimicrob Chemoth, 2004; 48: 4488-4490.
(49) Harrus S, Waner T, Bark H, Jongejan F, Cornelissen AW. Recent advances in determining the pathogenesis of canine monocytic ehrlichiosis. J Clin Microbiol, 1999; 37(9): 27452749 .

(50) Gal A, Loeb E, Yisaschar-Mekuzas Y, Baneth G. Detection of Ehrlichia canis by PCR in different tissues obtained during necropsy from dogs surveyed for naturally occurring canine monocytic ehrlichiosis. Vet J, 2008; 175(2): 212-217.

(51) Baneth G, Harrus S, Ohnona FS, Schlesinger Y. Longitudinal quantification of Ehrlichia canis in experimental infection with comparison to natural infection. Vet Microbiol, 2009; 136: 321-325.

(52) Aguirre E, Sainz A, Dunner S, Amusategui I, López L, Rodríguez- Franco $\mathrm{F}$ et al. First isolation and molecular characterization of Ehrlichia canis in Spain. Vet Parasitol, 2004; 125: 365-372.

(53) Kocan A, Crowder Levesque G, Whitworth LC, Murphy GL, Ewing SA, Barker RW. Naturally ocurring Ehrlichia chaffeensis infection in coyotes from Oklahoma. Emerg Infect Dis, 2000; 6: 477-480.

(54) Gutiérrez GCN, Martínez AMC, Triana-Alonso FJ. Identificación microscópica y molecular de ehrlichias en perros del estado Aragua-Venezuela. Salus, 2008; 12: 197-204.

(55) Nakaghil ACH, Machado RZ, Costa MT, André MR, Baldani CD. Canine ehrlichiosis: clinical, hematological, serological and molecular aspects. Cienc Rural, 2008; 38(3):766-770.

(56) Rojas-Triviño A, Rueda-Hurtado A, Díaz-Molano DM, Mesa-Cobo NC, Benavides-Montaño JA, Imbachi-López $\mathrm{K}$ et al. Identificación de Ehrlichia canis (Donatien \& Lestoquard) Moshkovski mediante PCR anidada. Vet Zootec, 2013; 7: 37-48. 
(57) Harrus S, Waner T, Aizenberg I, Foley JE, Poland AM, Bark H. Amplification of ehrlichial DNA from dogs 34 months after infection with Ehrlichia canis. J Clin Microbiol, 1998; 36(1): 73-76.

(58) Pat-Nah H, Rodríguez-Vivas RI, Bolio-Gonzalez ME, Villegas-Perez SL, Reyes-Novelo N. Molecular Diagnosis of Ehrlichia canis in dogs and ticks Rhipicephalus sanguineus (Acari: Ixodidae) in Yucatan, Mexico. J Med Entomol, 2015; 52(1): 101-104.

(59) Peleg O, Baneth G, Eyal O, Inbar J, Harrus S. Use of chimeric DNA-RNA primers in quantitative PCR for detection of Ehrlichia canis and Babesia canis. Appl Environ Microbiol, 2009; 75: 6393-6398.

(60) Peleg O, Baneth G, Eyal O, Inbar J, Harrus S. Multiplex real-time qPCR for the detection of Ehrlichia canis and Babesia canis vogeli. Vet Parasitol, 2010; 173: 292-299.

(61) Hsieh YC, Lee CC, Tsang CL, Chung YT. Detection and characterization of four novel genotypes of Ehrlichia canis from dogs. Vet Microbiol, 2010; 146: 70-75.

(62) Kamani J, Lee CC, Haruna AM, Chung PJ, Weka PR, Chung YT. First detection and molecular characterization of Ehrlichia canis from dogs in Nigeria. Res Vet Sci, 2013; 94: 27-32.

(63) Zweygarth E, Cabezas-Cruz A, Josemans Al, Oosthuizen MC, Matjila PT, Lis K et al. In vitro culture and structural differences in the major immunoreactive protein gp36 of geographi- cally distant Ehrlichia canis isolates. Ticks Tick Borne Dis, 2013; 5(4): 423-431.

(64) Faria JL, Dagnone AS, Munhoz TD, Joao CF, Pereira WA, Machado RZ et al. Ehrlichia canis morulae and DNA detection in whole blood and spleen aspiration samples. Rev Bras Parasitol Vet, 2010; 19: 98-102.

(65) Muangchuen A, Chaumpluk P, Suriyasomboon A, Ekgasit S. Colorimetric detection of Ehrlichia canis via nucleic acid hybridization in gold nano-colloids. Sensors, 2014; 14: 14472-14487.

(66) Jiménez-Coello M, Pérez-Osorio C, Vado-Solís I, Rodríguez-Buenfil JC, Ortega-Pacheco A. Serological survey of Ehrlichia canis in stray dogs from Yucatán, México, using two different diagnostic tests. VBZD, 2009; 9(2): 209211.

(67) Munderloh UG, Liu Y, Wang M, Chen C, Kurtti TJ. Establishment, maintenance and description of cell lines from the tick Ixodes scapularis. J Parasitol, 1994; 80: 533-543.

(68) De Farias RTE, Araújo AHK, da Silva KF, Lira SV, Fernandes VI, Labruna MB et al. Survey of Ehrlichia canis, Babesia spp. and Hepatozoon spp. in dogs from a semiarid region of Brazil. Braz J Vet Parasitol, 2015; 24(1): 52-58.

(69) Wei L, Kelly P, Ackerson K, El-Mahallawy HS, Kaltenboeck B, Wang C. Molecular detection of Dirofilaria immitis, Hepatozoon canis, Babesia spp., Anaplasma platys and Ehrlichia canis in dogs on Costa Rica. Acta Parasitologica, 2014; 60(1): 21-25. 